\title{
The Effect of Intellectual Capital on Jordanian Tourism Sector's Business Performance
}

\author{
Abdel-Aziz Ahmad Sharabati, Abdel-Rahman Khaled Radi, Abdel-Naser Ibrahim Nour, \\ Abdel-Bari Ibrahim Durra and Kamel Mohammad Moghrabi \\ Business Faculty, Middle East University, Amman, Jordan
}

\begin{abstract}
This study aims at investigating the influence of Intellectual Capital (IC) on Jordanian Tourism (JT) organizations' Business Performance (BP). To approach the aim of the study, practical data were used in the empirical analysis collected from 205 managers (organizations) out of 490 managers (organizations), by means of a questionnaire. Statistical techniques such as descriptive statistics, t-test, ANOVA test, correlation, multiple regressions and stepwise regression were employed. To confirm the suitability of data collection instrument, a Kolmogorov-Smirnov, Cronbach's Alpha and Factor Analysis were used. The results of the study indicated a positive significant relationship between IC and JT organizations' BP. However, the RC indicators were the most important indicators to distinguish the organizations from one another, followed by HC, while still they have a lot of work to improve SC. The empirical analysis showed that only RC and HC affect JT organizations' BP, while SC did not show any significant effect on JT organizations' BP. Furthermore, empirical results indicated that there are strong inter-relationships and interactions among the three components of IC with each others. The use of a single industry study design limits its generalisability to other industries. The data is also limited to Jordanian organizations; therefore, generalizing results of a Jordanian setting to other countries may be questionable. Extending the analysis to other settings represent future research opportunities. The data suggest that a similar set of IC indicators could be developed for other organizations and industries whether government, public or private, profitable or non-profitable organizations.
\end{abstract}

Key Words: Intellectual capital, human capital, structural capital, relational capital, Jordanian tourism organizations, business performance

\section{Introduction}

Intellectual capital is one of the subjects that have been recently tackled by different researchers for its importance to almost all organizations, industries and countries. Most researchers studied the intellectual capital within different industries and sectors, but very few of them took the initiative to deal with intellectual capital within Tourism industry. Tourism is Jordan's largest industry, as at end of 2008, its contribution to Jordan's GDP stood at $14 \%$ (Tourism Awareness Survey Full Report, 2009) and accounted for over 12.4\% of Jordan's GDP in 2010 (Minister of Tourism and Antiquities, 2011). Tourism industry should be knowledge intensive and highly innovative industry in order to gain a competitive edge i.e. tourism organizations provide a mixture of more intangible forms of intellectual capital like people's knowledge and skills than tangible ones like patents and brand names. Djilali et al. (2012) defined IC as the total stocks of all kinds of intangible assets: knowledge, capabilities, and relationships, at employee level and organization level, within a company.

All countries around the world wish to have famous touristic places, and those countries that have such places should give special care to preserve and promote such places all over the world to attract tourists to visit such places. Tourism sector can create a huge income in foreign currency, which can contribute to economic growth. Serrano (2003) stated: Glasgow used to be a heavy industry hub and now tourism retailing and financial services are as important as manufacturing. Hotel plays a very important role, not just as tourism infrastructure but also as a business platform to facilitate economic transactions. Furthermore, Blajovici (2007) asked: Why Romania or other countries in the Balkans such as Bulgaria touristic places are attracting a lot of people? One of the reasons may reside in the fact that traditions and historical places in the Eastern Europe and Balkans are well preserved and also different 
from the Western tradition and, thus, more attractive; this is an advantage which can be easily turned into a tourism capital. Moreover, Chaiboonsri and Chaitip (2008) clarified that: Thailand was selected as a first in the "Best hospital-City to visitors" category and first in the "Country with greatest value for money: shopping" category. Most importantly, Thailand placed first in the "Tourism Capital of Asia" category at $34 \%$, while China was second at $17 \%$ and Japan third at $13 \%$ (Foreign Office: The Government Public Relations Department, 2005). Heck (2011) said: One of the fastest growing tourism markets worldwide is the cultural tourism. Finally, Dragoş and Ravar (2012) stated that: Today, tourism represents much more than a service category; it is a complex industry, exerting a strong multiplier effect on the activity of various economic sectors, such as agriculture, commerce, and constructions. Tourism capital originates from historical, natural (Waterfalls), and entertainment (Disneyland) places, as well as, people's knowledge, experience, skills, systems and programs related to tourism, relationships and government support.

Jordan has many famous Touristic (historical, holistic (religious) and natural) places such as Petra (one of the world's seven wonders), Jarash, Mount Nebo, Wadi Rum, Baptism of the Dead See, and the Dead See itself, plus unique traditional folklore and medical treatment sites. Blanke and Chiesa (2013) pronounced that: According to Travel and Tourism Competitiveness index, Jordan was number 64 in 2011 and number 60 in 2013. Regionally (Middle East and North Africa), Jordan was number 6. So, when comparing Jordan with other countries which may have almost similar unique touristic places and unique traditions such as Egypt (Pyramids), Palestine (Israel) Churches and Mosques, India, China, Europe, then we can easily ask: Why Jordan is lagging behind? Is the reason related to the touristic places or people working in this sector, or promotion or government or infrastructure (hotels, restaurants and roads) or culture (hospitality). Where is the problem, it seems that the problem is in people working in this industry and the support of the government, because Jordan has a fantastic and unique touristic places equivalent to Egypt and Palestine (Israel) and has unique tradition (folklore). Ewa (2010) stated that: Tourism may become a major force driving the Jordanian economy and a starting point for the development of many other sectors.

If the problem is in people's knowledge, experience, systems and programs, and relationships (these are the main components of intellectual capital) then we have to answer another question: How we can measure and manage intellectual capital to improve performance? Roos and Roos (1997) said that we have to measure what we would like to manage. Aurelia (2007) explained that: The problem of designing measurements and evaluation of intellectual capital has not been fully resolved. But the models of measurements and evaluation of knowledge and intellectual capital can serve different specific purposes of different organizations. Moreover, Mavridis (2008) stated that: Indeed the real matter of intellectual capital or knowledge management is still not fully understood or not practically "realized". Therefore, this research aims to adapt measurement indicators to measure intellectual capital within tourism sector, and tries to investigate its effect on Jordanian tourism sector's business performance, to provide sound recommendations to concerned organizations, industries and decision makers.

\section{Literature Review}

It seems that the availability of touristic places and unique traditional culture (folklore) are not the only factors which affect the attraction of tourists. Hospitality, the people working in this sector, advertisement (promotion) and government support are also very crucial factors to touristic business. These factors depend upon the country's infrastructure: hard and soft infrastructure. The hard infrastructure including hotels, restaurants, roads...etc., while soft infrastructure includes the culture, hospitality, education, experience and skills of the host country's people, especially who plan, attract and deal with tourists. At the same time it includes systems and programs, and relationships, as well as, government support. These are called intellectual capital.

Many previous studies indicated that intellectual capital is positivity and significantly affect tourism sector's business performance and in turn affects country's economic development. Cabrita and Bontis (2008) study results indicated that the three constructs that make up intellectual capital really affect one another. Decomposition of effects reveals that Human Capital (HC) has important effects on both structural capital (0.755) and relational capital (0.391). Human capital influences relational capital not only directly $(0.391)$ but also indirectly through the structural capital $(0.755 \times 0.405=0.306)$, giving a total effect of 0.697. Moreover, human capital also influences business performance indirectly. Adam, and Urquhart (2009) concluded that the role of cognitive capital is the most important for the tourism sector of the Maldives, and may play a vital role in accumulating structural and relational capital, together with appropriate government policies. Sundac and Krmpotic (2009) study revealed that: The 
synergy of human, structural and consumer capital can result in strong intellectual capital that becomes the source of competitive advantage and value added. Jerman et al. (2009) results demonstrated that larger touristic companies do really employ a greater proportion of intangibles, although the size of a company has just a minimal influence on the state of intangibles. Sharabati et al. (2010) found that there was a positive significant effect of IC on Jordanian manufacturing pharmaceutical organizations' BP, they also found that RC and HC affect BP, while SC did not. Daud and Yusoff (2011) findings showed that the combination of knowledge management processes as organizational capability with intellectual capital as organizational strategic assets facilitates improvements in organizational performance. Carrington and Tayles (2011) concluded: Intellectual capital can be a major factor that can aid Caribbean policy makers as the region transitions from agricultural based to services based economies with tourism being the largest contributor to GDP. The study showed that HC, RC and $\mathrm{SC}$ are related to sense-making, that measurement of IC is associated with performance, that measurement of IC mediates the relationships between $\mathrm{RC}$ and performance and SC and performance, and it validates the relationship between $\mathrm{HC}$ and performance. Ling (2011) confirmed that intellectual capital does enhance a firm's global initiatives, and intellectual capital complementarities have positive impact on a firm's global initiatives (global innovation and global marketing) in both high and low dynamic context.

Gabriela et al. (2012) stated: The intellectual capital consists of stocks and flows of knowledge available in an organization. They can be regarded as intangible assets, and together with tangible resources compose the market value of a business. Ussi (2012) made obvious that: Tourism is perceived as one of the world's fastest growing service sectors and a major source of economic development and environmental and cultural conservation for many, if not all, developing countries. Alexandru and Janeta (2012) concluded that: It is very important to invest on human capital which can contribute to economic and social development of countries. Djilali et al. (2012) results indicated that without human capital (as a part of intellectual capital) nothing can be accomplished, and without well-trained, welldeveloped, well-appreciated, and well-managed human capital, modern organizations of government and business cannot meet the challenges of the globalization age. Tsen (2013) stated: The $21^{\text {st }}$ century is the era of knowledge economy. Intellectual capital has replaced labor and capital as the most important assets of companies. Carrington (2013) study found a significant and positive relationship between measurement of IC and performance. Majdalany and Henderson (2013) findings indicated a statistically positive relationship between human capital, relational capital, structural capital, human liabilities, relational liabilities, and structural liabilities on one hand, and Return on Equity (ROE). Sharabati et al. (2013) results showed a positive significant effect of IC on Jordanian Telecommunication Companies' $\mathrm{BP}$. The results also indicated that $\mathrm{RC}$ is positively and significantly affect $\mathrm{BP}$, then $\mathrm{HC}$, while SC does not significantly affect BP. The Empirical results also indicated that there are strong inter-relationships and interactions among the three components of IC.

From the literature review above, it can be concluded that IC consists of three main components: human capital (HC), structural capital (SC) and relational capital (RC). These three components are the main constituent of almost all organizations' intangible assets. At the same time, almost all researchers, scholars and decision makers agreed upon the fact that the effect of IC components on organizations' performance can not be ignored. Therefore, the current study is an attempt to investigate the impact of IC components on tourism organizations' performance in Jordan, consequently to provide sound recommendations on how to develop the IC components for further performance improvement.

\section{Study Purpose and Objectives}

This study investigates the effect of IC management on the Jordanian Tourism Sector's business performance. More specifically, this study intends to answer the following question: Is there a direct impact of IC elements on JT organizations' BP? The main objective of this research is to provide recommendations about performance measurement within IC context to JT organizations, industries, and decision makers.

\section{Study Importance and Scope}

The current study partially focuses on managerial norms, and partially on social norms. A better understanding of the effect of IC elements on the JT organizations' BP draws conclusions that can be beneficial not only for JT organizations but also to other organizations, institutions, industries and policy makers (government). The content also may be of an interest to academic studies related to the reporting and decision making concerning IC. This study presents the problem at an organizational level, as it is the level of implementing strategies and management. The current study might be considered as an initiative that presents the effect of IC on JT organizations' BP. 


\section{Problem Statement}

The problem of defining, measuring and managing IC is not limited to one organization, industry, or country, but it is a worldwide problem (Tayles et al., 2005). The problem of designing measurements and evaluation of intellectual capital has not been fully resolved (Aurelia, 2007). Indeed the real matter of intellectual capital or knowledge management is still not fully understood or not practically "realized" (Mavridis, 2008). Furthermore, Sharabati, et al. (2010) stated: The concept of IC is not well known to most managers in Jordan. Moreover, Manzari et al. (2012) specified that every organization should select its appropriate IC definition and its indicators to measure it. Therefore, the purpose of this research is to assign suitable measurement indicators and to investigate the effect of IC elements on JT organizations' BP.

\section{Problem Elements}

The study problem can be perceived by having detailed and scientific answers to the following questions:

The main question: Is there a direct impact of IC on JT organizations' BP?

This main question can be divided into three questions according to IC elements as follows:

1. Is there a direct impact of the $\mathrm{HC}$ on JT organizations' BP?
2. Is there a direct impact of the SC on JT organizations' BP?

3. Is there a direct impact of the RC on JT organizations' BP?

\section{Study Hypotheses}

Based on the above-mentioned problem statement and its elements, and according to the study model, the following hypotheses can be developed:

H0: IC variables do not have a direct impact on JT organizations' BP, at $\alpha=0.05$.

This main hypothesis can be divided into three hypotheses according to the IC elements (variables) as follows:

H0.1: HC does not have a direct impact on JT organizations' BP, at $\alpha<0.05$.

H0.2: SC does not have a direct impact on JT organizations' $\mathrm{BP}$, at $\alpha<0.05$.

H0.3: RC does not have a direct impact on JT organizations' $\mathrm{BP}$, at $\alpha<0.05$.

\section{Study Model}

Whatever the classification used in any research or literature to classify IC, the aim is to understand, measure and manage the IC. This study uses the most widely used classification model that is fundamentally based on both Stewart's and Bontis's classification as shown in figure (1): HC, SC and RC.

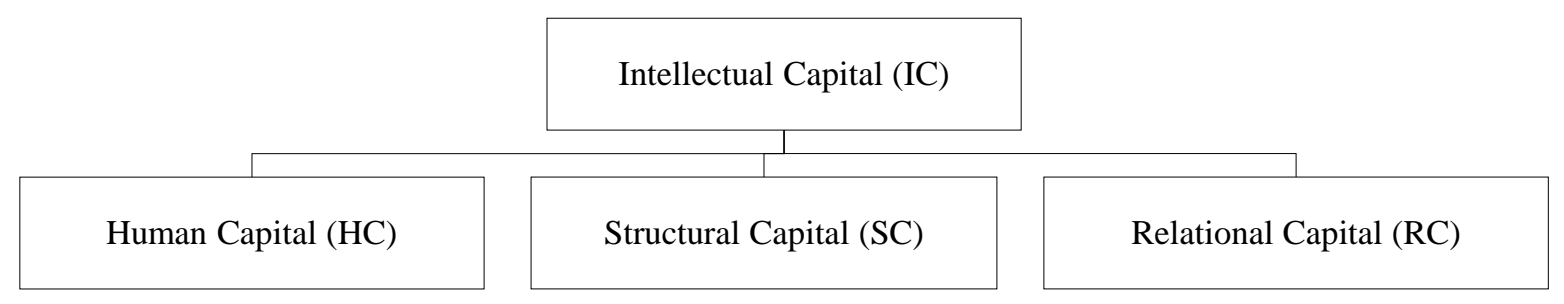

Figure 1. Study Basic Model.

The current research studies the effect of IC variables on JT organizations' BP as shown in the study model figure (2).

\begin{tabular}{|l|l|}
\hline \multicolumn{2}{|c|}{ Dependent Variable } \\
\hline Intellectual Capital: & Independent Variables \\
1. Human Capital (HC) & \\
2. Structural Capital (SC) & \\
3. Relational Capital (RC) & \\
\hline
\end{tabular}

Figure 2. Study Model. 


\section{Data Collection Methods and Procedures}

\section{Study design and nature}

One of the ways to validate the theme of the current research is to investigate how organizations use their IC to improve performance. In order to empirically validate the study's model, a survey method was conducted in line with earlier studies. The data were collected from managers at JT organizations. The collected data verified through the SPSS 20 focusing on the correlation among IC elements and their relationships with JT organizations business performance. The current study is considered as a causality study, because it aimed at investigating the cause/effect relationship between IC elements and JT organizations' BP. It started with literature review and experts' interviews to develop the currently used measurement model. Then, a panel of judges was conducted to finalize the items to be included in the questionnaire. Finally, the survey was carried out, and the results were compared with previous researches.

\section{Population, sample and unit of analysis}

At the time of the study, the total number of tourism offices were about 490 in Amman, the entire population was targeted to explore the topic of IC, thus negating any need for sampling. The survey unit of analysis was composed of all managers (manager for each organization) working at JT organizations.

\section{The questionnaire}

One of the main tools in actualizing a research project is the development of a tested instrument. Initial items to measure various constructs were developed depending on prior researches. With the help of experts the questionnaire was designed and developed in contrast with hypotheses and research model. Then the questionnaire was validated through expert interviews and a panel of judges.

\section{Questionnaire variables}

Independent variables (IC): Through literature review, the researchers have identified three important independent variables of IC that contribute to JT organizations' BP: HC, SC and RC. Each was tested by 15 questions. Dependent variable of the study is related to JT organizations' BP. BP was measured through the following 10 indicators (see analysis). All variables were measured by five-point Likert-type scale to tap into the individual's perceptions, ranging from value 1 (strongly disagree) to value 5 (strongly agree) used throughout the questionnaire.

\section{Data Analysis}

Questionnaires were delivered to 300 out of 490 managers. This resulted in sample rate of about $61 \%$ of the total population. The researchers gathered only 240 questionnaires, only 205 questionnaires were suitable for further analysis, representing $41.8 \%$ of the total unit of analysis.

\section{Normal distribution (Kolmogorov-Smirnov Z Test)}

In order to verify the normal distribution of variables, the researchers carried out Kolmogorov-Smirnov (KS) Z test. All dependent and independent variables were tested for normality. If the significance level was more than 5 percent, normality was assumed (Bollen et al., 2005, Sharabati et al., 2010). Table (1) shows that all the independent and dependent variables are normally distributed.

Table 1. Normality Test: One-Sample Kolmogorov-Smirnov (Z) Test.

\begin{tabular}{lll}
\hline Variables & $(\mathrm{K}-\mathrm{S}) \mathrm{Z}$ & Sig. \\
\hline Human Capital & 1.151 & 0.141 \\
Structural Capital & 1.100 & 0.178 \\
Relational Capital & 1.200 & 0.112 \\
Intellectual Capital & 1.262 & 0.083 \\
Business Performance & 1.125 & 0.159 \\
\hline
\end{tabular}




\section{Reliability test (Cronbach's Alpha)}

The reliability was evident by strong Cronbach's alpha coefficients of internal consistency. If Alpha Coefficients were above 0.80 , they were considered high, and if they were above 0.75 , they were accepted, while if they were below 0.60 , then results indicated weak internal inconsistency (Bollen et al.,
2005), while Sharabati et al. (2010) stated that Alpha coefficients above 0.7 are accepted. As shown in table (2), the results of Cronbach's alpha were registered acceptable; however, Cronbach's Alpha results were between 0.849 and 0.940 . The above result also matches with Bin Ismail (2005), Moslehi et al. (2006) and Sharabati et al. (2010) studies.

Table 2. Research Cronbach's Alpha.

\begin{tabular}{lcc}
\hline & Variables & Alpha \\
\hline Human Capital & & 0.883 \\
Structural Capital & & 0.871 \\
Relational Capital & 0.880 \\
Intellectual Capital & 0.940 \\
Business Performance & 0.849 \\
\hline
\end{tabular}

\section{Validity}

Two methods were used to confirm validity: First, multiple sources of data (literatures, expert interviews and panel of judges) were used to develop and refine the model and measures. Then, factor analysis was carried out for all items included in the questionnaire.

Factor analysis (Pearson's principal component analysis)

Factor analysis was used to measure the validity of each item (loading) within its variable and how each variable is loaded within IC. According to Bin Ismail (2005), Bollen et al. (2005) and Sharabati et al. (2010) factor loading value below 0.4 should be removed. Table (3) shows that all variables and variable items were valid, since their factor loading values were more than 0.4 .

Table 3. Factors Loading for Dependent and Independent Variables.

\begin{tabular}{lccc}
\hline & IC Variables & Factor 1 & Extraction \\
\hline Human Capital & & 0.817 & 0.668 \\
Structural Capital & 0.863 & 0.744 \\
Relational Capital & 0.874 & 0.764 \\
Intellectual Capital & 0.988 & 0.976 \\
Business Performance & 0.785 & 0.616 \\
\hline
\end{tabular}

\section{Study variables analysis}

Dependent and Independent Variables

Table (4) shows that the average means of the respondents' perception about the implementation of IC variables were ranging from 3.096 to 3.591 , with standard deviation that ranges from (0.493 to 0.516$)$. Such results indicate that there is an agreement among JT organizations on that they have medium implementation of IC variables. The overall result indicates that there is significant implementation of the IC variables within JT organizations, where the total average mean was 3.353 and $(\mathrm{t}=11.646>$ 1.645). The table (4) also shows that the average means of the respondents' perception about the role of BP indicators was 3.735, with standard deviation (0.472). Such results indicate that there is an agreement on the role of BP indicators. The result indicates that there is a significant role of performance indicators, where $(t=22.309>1.645)$. 
Table 4. Mean, Standard Deviation and One-Sample T-Test Results for All Variables.

\begin{tabular}{lcccc}
\hline \multicolumn{1}{c}{ Variables } & Mean & Std. deviation & T value & T tabulated \\
\hline Human Capital & 3.371 & 0.516 & 10.303 & 1.645 \\
Structural Capital & 3.096 & 0.493 & 2.777 & 1.645 \\
Relational Capital & 3.591 & 0.501 & 16.881 & 1.645 \\
Intellectual Capital & 3.353 & 0.433 & 11.646 & 1.645 \\
Business Performance & 3.735 & 0.472 & 22.309 & 1.645 \\
\hline
\end{tabular}

Relationships between the study variables

Before testing the hypotheses, Pearson correlation (r) was carried out to test the correlation among the responses of IC variables, then between them and performance indicators. If there is a relationship between IC and JT organizations' BP then we can continue further analysis.

Table 5. Pearson's Correlation (r) Among Independent Variables, and with Dependent Variable

\begin{tabular}{lccccc}
\hline \multicolumn{1}{c}{ Variable } & HC & SC & RC & IC & BP \\
\hline Human Capital & & & & & \\
Structural Capital & $0.596^{* *}$ & & & & \\
Relational Capital & $0.562^{* *}$ & $0.681^{* *}$ & & & \\
Intellectual Capital & $0.840^{* *}$ & $0.878^{* *}$ & $0.867^{* *}$ & & \\
Business Performance & $0.544^{* *}$ & $0.558^{* *}$ & $0.656^{* *}$ & $0.680^{* *}$ & \\
\hline * Correlation is significant at 0.01 levels (2-tailed) & & & &
\end{tabular}

Pearson correlation matrix table (5) shows that the relationships among the IC variables are strong, where $\mathrm{r}$ ranges from 0.562 to 0.681 . The matrix also indicates that the relationship between the total IC and each IC variable is very strong, where $r$ ranges from 0.840 to 0.878 . The matrix also showed that the relationship between IC variables and JT organizations' BP is strong, where $r$ ranges from 0.544 to 0.656 . For total IC $\mathrm{r}$ reaches 0.680 , which indicates a very strong relationship between IC and JT organizations' BP.

\section{Hypotheses testing}

To test hypotheses, a multiple regression analysis will be used to analyze the relationship between the IC variables and JT organizations' BP. If regression analysis is robust against linearity, normality, equal variance, independence of errors, and multicollinearity, then multiple regressions will be applicable in the case at hand. Also the coefficient of determination $\left(\mathrm{R}^{2}\right)$ indicates the goodness and fitness of the model.

\section{The main hypothesis}

Ho: IC variables do not affect the JT organizations' $\mathrm{BP}$, at $\alpha=0.05$.

Before conducting the multiple regression models, the researchers tested the underlying assumption of the test:

-Independence of errors: To test this assumption, Durbin Watson test is conducted, where $(\mathrm{d}=1.774)$, which approximately equals two. This indicates that the residuals are not correlated with each other; therefore, the independence of errors is not violated. -Multi-Collinearity: From table (6), the VIF value is less than 10 and the Tolerance value is more than 0.2. This indicates that there is no multi-collinearity within the independent variables of the study.

Table 6. Multi-Collinearity Test for the Main Hypothesis:

\begin{tabular}{lcc}
\hline \multicolumn{1}{c}{ Intellectual capital Sub-variables } & \multicolumn{2}{c}{ Multi-Collinearity Statistics } \\
\cline { 2 - 3 } & Tolerance & VIF \\
\hline Human Capital & 0.599 & 1.669 \\
Structural Capital & 0.470 & 2.128 \\
Relational Capital & 0.498 & 2.007 \\
\hline
\end{tabular}


After achieving the underlying assumption of the regression model, the researchers conducted the following analysis:

Table 7. Results of Multiple Regressions Analysis: Regressing IC Variables against Performance

\begin{tabular}{lccccc}
\hline & Variable & $\mathrm{r}$ & $\mathrm{R}^{2}$ & F- Value & Sig. \\
\hline IC Variables & & 0.765 & 0.483 & 62.471 & 0.000 \\
\hline
\end{tabular}

The results of the multiple regression analysis that regress the three variables of the IC are shown on table (7) above. The three variables together explained 48.3 percent of the variance, where $\left(\mathrm{R}^{2}\right.$ $=0.483, \mathrm{~F}=62.471$, Sig.=0.000), therefore, the null hypothesis is rejected and the alternative hypothesis is accepted, which indicates that the IC variables affect the JT organizations' BP, at $\alpha=0.05$. The following table shows the significant effect of each variable within the IC.

The conclusion of table (8) shows that the RC variable has the highest effect on JT organizations'
BP, where (Beta $=0.426$, sig. $=0.000)$. Thus, it indicates that the $\mathrm{RC}$ variable is the most significant and positively and directly regresses to the JT organizations' $\mathrm{BP}$, followed by $\mathrm{HC}$ variable, where (Beta=0.219, sig.=0.001), while SC variable has the lowest effect or no significant effect on JT organizations' BP, where (Beta $=0.119$, sig. $=0.108)$. The relationship between the dependent and independent variables derived by this model can thus be expressed as:

$I C=1.178+0.200(H C)+0.114(S C)+0.426(R C)$.

Table 8. Un-standardized and Standardized Coefficients of Multiple Regression Model for IC Variables

\begin{tabular}{lccccc}
\hline \multicolumn{1}{c}{ IC Variables } & \multicolumn{2}{c}{$\begin{array}{c}\text { Un-standardized } \\
\text { Coefficients }\end{array}$} & $\begin{array}{c}\text { Standardized } \\
\text { Coefficients }\end{array}$ & & \\
\hline & B & Std. Error & Beta & t-value & $\mathrm{p}$ \\
\hline (Constant) & 1.178 & 0.189 & & 6.232 & $0.000^{*}$ \\
Human Capital & 0.200 & 0.060 & 0.219 & 3.341 & $0.001^{*}$ \\
Structural Capital & 0.114 & 0.071 & 0.119 & 1.613 & $0.108^{*}$ \\
Relational Capital & 0.426 & 0.068 & 0.452 & 6.288 & $0.000^{*}$ \\
\hline
\end{tabular}

*Calculate is less than 0.05

H0.1: HC variable does not have a direct impact on JT organizations' BP, at $\alpha=0.05$.

From table (8), it is concluded that there is a positive direct effect of the $\mathrm{HC}$ variable on the JT organizations' BP, where $($ Beta $=0.219$, sig. $=0.001)$. Since $(\mathrm{t}=3.241, p<0.05)$, the null hypothesis is rejected and the alternative hypothesis is accepted, which indicates that the $\mathrm{HC}$ variable affects the JT organizations' BP, at $\alpha=0.05$.

H0.2: SC variable does not have a direct impact on JT organizations' BP, at $\alpha=0.05$.

From table (8), it is concluded that there is no significant effect of the SC variable on the JT organizations' BP, where (Beta $=0.119$, sig. $=0.108$ ). Since $(\mathrm{t}=1.613, p>0.05)$, the null hypothesis is accepted, which indicates that the SC variable does not have significant effect on JT organizations' BP, at $\alpha=0.05$.

H0.3: RC variable does not have a direct impact on JT organizations' BP, at $\alpha=0.05$.

From table (8), it is concluded that there is a positive direct effect of the RC variable on the JT organizations' BP, where (Beta=0.426, sig. $=0.000)$. Since $(\mathrm{t}=6.288, p<0.05)$, the null hypothesis is rejected and the alternative hypothesis is accepted, which indicates that the $\mathrm{RC}$ variable affects the JT organizations' BP, at $\alpha=0.05$.

\section{Stepwise regression}

To determine which variables are important in this model, the researchers used stepwise regressions model, results are as shown in following tables: 
Table 9. Stepwise Regressions (ANOVA) for IC Variables.

\begin{tabular}{lccccl}
\hline Model & $\mathrm{r}$ & $\mathrm{R}^{2}$ & $\mathrm{~F}$ & Sig. & \multicolumn{1}{c}{ IC Variables } \\
\hline 1 & $0.656(\mathrm{a})$ & 0.431 & 153.726 & 0.000 & Relational Capital \\
2 & $0.690(\mathrm{~b})$ & 0.476 & 91.679 & 0.000 & Relational Capital \& Human Capital \\
\hline
\end{tabular}

From table (9), the first model of stepwise regression shows the importance of the RC variable, where $\left(\mathrm{R}^{2}=0.431, \mathrm{~F}=153.726\right.$, Sig.=0.000). The second model of stepwise regression shows the importance of the $\mathrm{RC}$ and $\mathrm{HC}$, where $\left(\mathrm{R}^{2}=0.476, \mathrm{~F}=91.679\right.$, Sig. $=0.000)$. Therefore, it is concluded that the second model increases $\mathrm{R}^{2}$ with 0.045 . This means that the $\mathrm{RC}$ variable alone explain $43.1 \%$ of the variance, while the second model explains $47.6 \%$ of the variance. This means that $\mathrm{HC}$ adds $4.5 \%$ to the first model. There is no third model of stepwise regression that includes SC, which means that SC does not have any significant effect on JT organizations' BP. The following table shows the relation between the IC variables and JT organizations' BP:

Table 10. Stepwise Regressions Model for Relational Capital variables.

\begin{tabular}{llccccc}
\hline & Model & \multicolumn{2}{c}{ Un-standardized Coefficients } & $\begin{array}{c}\text { Standardized } \\
\text { Coefficients }\end{array}$ & t & Sig. \\
\hline & & B & Std. Error & Beta & & \\
\hline 1 & (Constant) & 1.515 & 0.181 & & 8.381 & 0.000 \\
& RC & 0.618 & 0.050 & 0.656 & 12.399 & 0.000 \\
& (Constant) & 1.213 & 0.189 & & 6.434 & 0.000 \\
& RC & 0.483 & 0.058 & 0.512 & 8.317 & 0.000 \\
& HC & 0.234 & 0.056 & 0.256 & 4.159 & 0.000 \\
\hline
\end{tabular}

*sig. $<0.05$

From table (10) above, the first model of stepwise regression shows that there is a positive direct relation between $\mathrm{RC}$ variable and JT organizations' $\mathrm{BP}$, where beta equals 0.656 . The second model of stepwise regression shows that there is a positive direct relation between the $\mathrm{RC}$ variable and $\mathrm{HC}$ variable with JT organizations' BP, where beta equals 0.512 and 0.256 , respectively. There is no third model of stepwise regression which again proves that SC does not have any significant effect on JT organizations' BP.

\section{Results Discussions}

The overall result indicated that there were significant implementations of the IC variables within JT organizations. It also showed that respondents were almost similar in their preferences regarding IC indicators implementation, where there were agreements among JT organizations on that they have medium implementation of IC variables. Results also indicated that there was an agreement on the role of BP indicators.

Pearson correlation matrix showed that the relationships among the IC variables were strong and the relationship between IC variables and JT organizations' BP was strong also. These results are matching with Cabrita and Bontis (2008) study results which indicated that the three constructs that make up intellectual capital really affect one another, and either directly or indirectly influences business performance, and Adam, and Urquhart (2009) stated that the cognitive capital is the most important for the tourism sector of the Maldives, and may play a vital role in accumulating structural and relational capital, together with appropriate government policies. While Sundac and Krmpotic (2009) said that: The synergy of human, structural and consumer capital can result in strong intellectual capital that becomes the source of competitive advantage and value added.

The results of the multiple regression analysis revealed that the IC variables affect the JT organizations' BP. However, it indicated that the RC variable was the most significant and positively and directly regresses to the JT organizations' BP, followed by $\mathrm{HC}$ variable, while $\mathrm{SC}$ variable has the lowest effect or no significant effect on JT organizations' BP. First model of stepwise regression showed the importance of the RC variable. The second model of stepwise regression shows the importance of the $\mathrm{RC}$ and $\mathrm{HC}$, while $\mathrm{SC}$ excluded which indicated that SC did not have any significant effect on JT organizations' BP. This result is exactly 
matches with Sharabati et al. (2010) results which found that there was a positive significant effect of IC on Jordanian manufacturing pharmaceutical organizations' BP, they also found that RC and $\mathrm{HC}$ affect BP while SC did not. Furthermore, Carrington and Tayles (2011) showed that HC, RC and SC are related to sense-making, that measurement of IC is associated with performance. Moreover, Gabriela et. al. (2012) stated: The intellectual capital can be regarded as intangible assets, and together with tangible resources compose the market value of a business. Djilali et al. (2012) results indicated that without human capital (as a part of intellectual capital) nothing can be accomplished, and without well-trained, well-developed, well-appreciated, and well-managed human capital, modern organizations of government and business cannot meet the challenges of the globalization age. Carrington (2013) study found a significant and positive relationship between measurement of IC and performance. Finally, Majdalany and Henderson (2013) findings indicated a statistically positive relationship between human capital, relational capital, structural capital, human liabilities, relational liabilities, and structural liabilities on one hand, and Return on Equity (ROE).

\section{Conclusions}

Findings of the study support the theory that intellectual capital has the potential to become the new source of wealth in JT organizations, and support that intellectual capital has a direct and positive effect on JT organizations' business performance. These results are promising, because they revealed the possibility of investments in intellectual capital at a given point in time might have an influence on JT organizations' prosperity. Evidence from the study showed that respondents were similar in their preference regarding medium implementation of IC variables, which might suggest that respondents hold the view that the JT organizations have an average amount of intellectual capital.

It seems that the respondents were aware of the role of relational capital variable and human capital variable in JT organizations' business performance, and they strongly believe that the relational capital variable and human capital variable affect JT organizations' BP. Therefore, it seems that the JT organizations have strong interest towards a high level of relational capital variable then towards human capital variable. However, it seems that the JT organizations do not invest in developing systems and programs related to human capital.
It appears that the respondents agree on the idea that the JT organizations have a lower level of structural capital compared to human capital and relational capital. It also seems that the respondents agree on that the JT organizations have low interest level toward the structural capital variable compared with human and relational capital variables.

In conclusion, one may propose that JT organizations are still below the average when compared with the world-class organizations, in terms of the presence of structural capital. The current level and development of structural capital has a relationship with the leadership style and the overall managing and leveraging of intellectual capital in the JT organizations.

Pearson correlation showed that there is a strong and significant correlation among relational capital, human capital and structural capital and they are strongly related to JT organizations' business performance. This means that any activity done to improve the level of any intellectual capital component will have a significant effect on other components of intellectual capital and JT organizations' business performance. Hence, the proposed "Intellectual Capital" model is substantiated. The results indicated that managing the three intellectual capital elements together i.e. synchronizing and synergizing them with each other, will lead to leveraging intellectual capital to the maximum level, and consequently producing the maximum performance improvement for the JT organizations. Also it seems that the respondents highly agree when expressing their opinion regarding JT organizations' business performance improvement indicators. This indicates that the JT organizations are forward-looking organizations.

The results have shown that there is a strong need to investigate further the influence of intellectual capital on JT organizations' business performance. All business leaders should understand and appreciate the power of intellectual capital management effect on business performance. Implementing the suggested recommendations will further enhance the overall management and performance of JT organizations in the future.

\section{Research Limitations/Recommendations}

Intellectual capital should be of interest to both academicians and business practitioners, because the development and management of intellectual capital will require more dedication and effort in the future. The use of a single industry study design limits its generalisability to other industries. The data is also limited to Jordanian organizations; therefore, 
generalizing results of a Jordanian setting to other countries may be questionable. Extending the analyses to other settings represent future research opportunities, which can be done by the following ways: Further testing with larger samples within same industry is important, and including other industries will help mitigate the issue of generalizing conclusions on other organizations and industries. Moreover, further empirical researches involving data collection over diverse countries especially Arab countries are needed.

\section{Contributions/Practical Implications}

JT organizations have great potentials for future performance improvement. Nowadays, JT organizations are not too much behind other worldclass tourism organizations, with the increase level of the presence of organizations' intellectual capital, JT organizations can improve and attain better performance. Based on the research findings, effective management should leverage intellectual capital which improves business performance. The research makes significant theoretical and empirical contributions to literature regarding influence of IC on the organizations' BP. The research results might help both academics and practitioners to be more ready to understand the components of IC and provide insight into developing and increasing them within their organizations. IC is an important source of organizations' wealth and therefore it should be taken into serious consideration when formulating the JT organizations' strategy. This strategy formulation process can be enhanced by fully integrating IC into management practices. JT organizations should coordinate different perspectives of IC to improve JT organizations' BP and should assign scales for each of the three components of IC. Finally, the data suggest that a similar set of IC indicators could be developed for other organizations and industries whether government, public or private, profitable or non-profitable organizations.

\section{Expected Value}

The current research may be considered as initiative study that highlights the effect of IC on JT organizations' BP in Jordan. The empirical results of this study built on the previous researches on the relationship between IC and organizations' BP. This study also extends prior research's viewpoint about the linear relationship between IC and organizations' BP with empirical evidence. The results can provide the reference for further research about the relationship between IC and BP.

\section{References}

Adam, M.S., \& Urquhart, U. (2009). No Man is an Island: Social and Human Capital in IT Capacity Building in the Maldives. Science Direct: Information and Organization, 19 (2009), pp. 1-21. Available online at www.sciencedirect.com.

Alexandru, J., \& Janeta, W. (2012). Main Aspects Concerning Intellectual Services Productivity with Focus to Education. Conference Proceedings, Scientific Committee of the 8th Edition of the International Conference "European Integration - New Challenges" EINCO2012, May 25 - 26, 2012, Oradea, Romania. "The Annals of the University of Oradea. Economic Sciences" - Tom XXI, 2012, pp. 494-498.

Aurelia, S. (2007). Measurement and evaluation of intellectual capital. Revisra Tineril or Economisti, The Young Economists Journal, Year V, - No. 8, APRIL 2007, pp. 133-136. http://stat257.central.ucv.ro/rte.

Bin Ismail, M. (2005). The Influence of Intellectual Capital on the Performance of Telekom Malaysia (Telco). Unpublished Doctoral Dissertation, October 2005. Business \& Advanced Technology Centre. University of Technology Malaysia. Available at: www.eprints.utm.my/1352/1.

Blajovici, L. (2007). The Impact of the Development of the Rumanian Tourism and Agro Tourism in the Context of the EU Integration. National Scientific Symposium with International Participation: The Impact of Romania's Entry into the European Union on Agriculture, April 27, 2007, Scientific Papers, pp. 41-44. Bucharest, Rumania.

Blanke, J. \& Chiesa, T. (2013). The Travel \& Tourism Competitiveness Report 2013. Reducing Barriers to Economic Growth and Job Creation. World Economic Forum, Geneva.

Bollen, L., Vergauwen, P., \& Schnieders, S. (2005). Linking Intellectual Capital and Intellectual Property to Company Performance. Management Decision, Vol. 43 No. 9, 2005, pp. 1161-1185.

Cabrita, M.R. \& Bontis, N. (2008) 'Intellectual capital and business performance in the Portuguese banking industry', Int. J. Technology Management, Vol. 43, Nos. 1-3, pp. 212-237.

Carrington, D. (2013). The Influence of the Process of Measuring IC on Performance. Abstracts of Papers, Presented at the 5th European Conference on Intellectual Capital, University of the Basque Country, Bilbao, Spain, 11-12 April 2013, pp. 8.

Carrington, D., \& Tayles, M. (2011). The Mediating Effects of Sensemaking and Measurement on the Intellectual Capital and Performance Linkage. Proceedings of the 3rd European Conference on Intellectual Capital University of Nicosia, Cyprus 18-19 April 2011, pp. 113-122.

Chaiboonsri, C., \& Chaitip, P. (2008). A Structural Equation Model: Thailand's International Tourism Demand for Tourist Destination. Annals of the University of Petrosani, Economics, Vol. 8, No. 1, pp. 65-94.

Daud, S., \& Yusoff, W.F. (2011). How Intellectual Capital Mediates the Relationship between Knowledge Management Processes and Organizational Performance? African Journal of Business Management, Vol. 5, No. 7, pp. 2607-2617, 4 April, 2011. Available online at http://www.academicjournals.org/AJBM.

Djilali, B., Sarra, B., \& Faycal, M. (2012). Managing Intellectual Capital to Confront the Challenges of Globalization. Mediterranean Journal of Social Sciences, Vol. 3 (6) March 2012, pp. 179-187.

Dragoş, J.D., \& Ravar, A.S. (2012). Consideration on the Financing of Tourism Development and Promotion Strategies in Romania. "Ovidius" University Annals, Economic Sciences Series, Volume XII, Special Issue/2012, pp. 87-92.

Ewa, S. (2010). The Impact of Tourism on Jordan's Economy. Journal of Social and Economic Studies, pp. 205-210. Hungary, Nyíregyháza 2011. 
Gabriela, H.M., Dorinela, N., \& Alexandra, I. (2012). Learning Organization: The Importance of Innovation and Adaptation. "Ovidius" University Annals, Economic Sciences Series, Vol. XII, Special Issue 2, pp. 145-150.

Heck, I.V. (2011). The European Capital of Culture: Aims, Expectations, Outcomes and Co-operations in Relation to this High Profile Mega Event. Master Thesis, Economic Geography. Radboud University Nijmegen

Jerman, M., Kavcic, S., \& Kavcic, B. (2009). Intangibles as Future Value Creators: The Case of the Hotel Industry. Tourism and Hospitality Management, Vol. 15, No. 2, pp. 153-162.

Ling, Y.H. (2011). The Influence of Intellectual Capital on Organizational Performance in two Contexts. Proceedings of the 8th International Conference on Intellectual Capital, Knowledge Management \& Organisational Learning. The Institute for Knowledge and Innovation, Southeast Asia (IKISEA) of Bangkok University, Bangkok, Thailand, 27-28 October 2011, pp. 34.

Majdalany, G., \& Henderson, J. (2013). The Effect of Intellectual Assets and Intellectual Liabilities Disclosure on Financial Performance: An Empirical Analysis of Publicly Listed Companies in the United Arab Emirates. Abstracts of Papers, Presented at the 5th European Conference on Intellectual Capital, University of the Basque Country, Bilbao, Spain, 1112 April 2013, pp. 24-25.

Manzari, M., Kazemi, M., Nazemi, S., \& Pooya, A. (2012). Intellectual Capital: Concepts, Components and Indicators: A literature Review. Management Science Letters, 2 (2012), pp. 2255-2270.

Mavridis D.G. (2008). Intellectual Capital Management as Entrepreneurial Competences Drivers. Archives of Economic History / AU, XX/1/2008, pp. 37-66.

Minister of Tourism and Antiquities (2011). The National Tourism Strategy 2011-2015, For Jordan: Executive Summary. Supported by USAID

Moslehi, A., Mohagharl, A., Badie1, K., \& Lucas, C. (2006). Introducing a Toolbox for IC Measurement in the Iran
Insurance Industry. Tehran University. The Electronic Journal of Knowledge Management, Volume 4 Issue 2, 2006, pp. 169180.

Roos, G., \& Roos, J. (1997). Measuring your Company's Intellectual Performance. International Journal of Strategic Management. Long Range Planning, Vol. 30, No. 3, 1997, pp. 413-426.

Serrano, F.A. (2003). City Competitiveness and Attractiveness: A New Approach to Evaluate Economic Development in Mexican Cities. Doctoral Thesis, Department of Urban Studies, University of Glasgow. UK.

Sharabati, A.A, Jawad, S., \& Bontis, N. (2010). Intellectual Capital and Business Performance in the Pharmaceutical Sector of Jordan, Management Decision, Vol. 48, No. 1, pp. 105-131.

Sharabati, A.A., Nour, A.I., \& Shamari, N.S. (2013). The Impact of Intellectual Capital on Jordanian Telecommunication Companies' Business Performance. American Academic \& Scholarly Research Journal, Vol. 5, No. 3, pp. 32-46.

Sundac, D., \& Krmpotic, I.F. (2009). Measurement and Management of Intellectual Capital. Tourism and Hospitality Management, Vol. 15, No. 2, pp. 279-290.

Tayles, M., Webste, M., Sugden, D., \& Bramley, A. (2005). Accounting "Gets Real" in Dealing with Virtual Manufacturing. Journal of Intellectual Capital, Vol. 6 No. 3, 2005, pp. 322-338.

Tourism Awareness Survey Full Report (2009). Public Awareness and Attitudinal Research of Tourism in Jordan: A research study to gauge perceptions by Jordanians towards tourism, November 2009, Commissioned by Jordan Tourism Development Project II.

Tsen, Y.J. (2013). An Explanatory Analysis in the Construction of College Performance Indices. The International Journal of Organizational Innovation, Vol. 5 No. 3, January 2013, pp. 98-132.

Ussi, M.U. (2012). The Viability of Community Tourism in Least Developed Countries: The Case of Zanzibar. Doctorate Dissertation, University of Central Lancashire. 